\title{
Influence of a protective coating on the aging of epitaxial $\mathrm{YBa}_{2} \mathrm{Cu}_{3} \mathrm{O}_{7-x}$ films
}

\author{
P Brüllt, R Steinket, P Leiderert, J Schubert $¥, \mathbf{W}$ Zander $¥$ and \\ B Stritzker $\S$ \\ † Fakultät für Physik, Universität Konstanz, D-7750 Konstanz, Federal Republic of \\ Germany. \\ Institut für Schicht- und lonentechnik, Forschungszentrum Jülich, D-5170 Jülich, \\ Federal Republic of Germany. \\ $\S$ Institut für Physik, Universität Augsburg, Memmingerstr. 6, D-8900 Augsburg, \\ Federal Republic of Germany.
}

Received 18 December 1991

Abstract. The influence of aging and temperature cycling effects on thin epitaxial $\mathrm{YBa}_{2} \mathrm{Cu}_{3} \mathrm{O}_{7-x}$ films on (100) $\mathrm{SrTiO}_{3}$ has been investigated over a period of 15 months using measurements of the spatial magnetic field distribution. Two of the four investigated samples have an amorphous YBaCuO cover layer which appears to protect the samples against degrading.

\section{Introduction}

Epitaxial high- $T_{\mathrm{c}}$ films have recently been used successfully as the basic material for various components like miniaturized antennas or sQuDs operating far above liquid helium temperatures, and many more interesting applications appear feasible. An important requirement for such a practical use of high- $T_{c}$ superconductors is the resistance to degradation of the superconducting properties upon repeated temperature cycling to liquid nitrogen temperature, or simply aging under normal atmospheric conditions. Although it is commonly stated that epitaxial $\mathrm{YBa}_{2} \mathrm{Cu}_{3} \mathrm{O}_{7-x}$ films are quite robust and insensitive to temperature cycling, moisture or just aging in the atmosphere for periods of several months, quantitative results are sparse $[1,2]$. Here we report on investigations - carried out over a period of more than one year-of aging effects of epitaxial $\mathrm{YBa}_{2} \mathrm{Cu}_{3} \mathrm{O}_{7-x}$ films on (100) $\mathrm{SrTiO}_{3}$ substrates. In order to obtain information about the film quality across the total area of the films $\left(1 \times 1 \mathrm{~cm}^{2}\right)$ a contactless method was used where the spatial field distribution $B(x)$ above the sample is measured as a function of an external field $B_{\text {ext }}$ applied in a direction perpendicular to the film. Special attention was paid to the influence of a cover layer added as a protective coating against environmental influences.

\section{Experiment}

The measurements of the spatial field distribution $B(x)$ were partly performed with a vibrating coil method in liquid nitrogen and in the magnetic field range $0-60 \mathrm{G}$
[3]. More recent measurements were carried out in a cryostat which allowed the temperature to vary between 15 and $300 \mathrm{~K}$ and in the field range 0-120 G. Here we used a cryogenic Hall probe with an active area of $0.2 \times 0.2 \mathrm{~mm}^{2}$, which was scanned across the sample at a distance of $0.2 \mathrm{~mm}$. Both probes, due to their orientation, picked up only the local magnetic field component parallel to the external field.

Four samples were prepared under similar conditions (properties listed in table 1), two of them (B, D) with an additional cover layer. All four films have been prepared in situ without postannealing by laser ablation, as described earlier $[4,5]$. The use of a cylindrical rotating target in combination with a line-focused laser beam means that a divergent plume of ablated material will ensure the condensation of a homogeneous high quality film over the whole substrate area of $1 \times 1 \mathrm{~cm}^{2}$. With this arrangement areas of about $1.5 \times 1.5 \mathrm{~cm}^{2}$ can now be coated homogeneously. Epitaxial $\mathrm{YBa}_{2} \mathrm{Cu}_{3} \mathrm{O}_{7=x}$ films were grown using the standard procedure on (100) $\mathrm{SrTiO}_{3}$ substrates heated to about $750^{\circ} \mathrm{C}$. After condensation of the film the heater was switched off and the vacuum system flooded with $\mathrm{O}_{2}$. Then films $\mathrm{A}$ and $\mathrm{C}$ were removed from the system

Table 1. Sample properties.

\begin{tabular}{|c|c|c|c|c|}
\hline Sample & $\begin{array}{l}\text { Cover } \\
\text { layer }\end{array}$ & $\begin{array}{l}\text { Max } B_{\text {shueld }} \\
\text { (initial) } \\
\text { at } 77 \mathrm{~K} \\
\text { (G) }\end{array}$ & $\begin{array}{l}\text { Treatment } \\
\text { (cycles } \\
300-77-300 \mathrm{~K} \text { ) }\end{array}$ & $\begin{array}{l}\text { Max } B_{\text {shield }} \\
\text { (final) } \\
\text { at } 77 \mathrm{~K} \\
\text { (G) }\end{array}$ \\
\hline A & no & 22 & 4 & 3 \\
\hline B & yes & 25 & 4 & 26 \\
\hline C & no & 19 & 20 & 16 \\
\hline$D$ & yes & 23 & 20 & 30 \\
\hline
\end{tabular}


immediately. Films B and D were treated differently. Directly after the first deposition there was a second deposition, during which the substrate heater was switched off. In this way we obtained an amorphous YBaCuO layer on top of the superconducting films in situ without any contact with the ambient air.

All samples were stored in the atmosphere during the time between the measurements. In addition, samples $\mathrm{C}$ and $\mathrm{D}$ were cycled four times between $300 \mathrm{~K}$ and $77 \mathrm{~K}$ between subsequent measurements. The moisture film that developed on the sample surface during warm-up was not removed. Measurements of the magnetic flux distribution of both pairs were repeated several times at intervals of about two months over a period of nine months, and a final test was performed after 15 months.

The $B(x)$ traces were taken under zero field cooling (ZFC) conditions. Field distributions were measured with the external field applied (shielding), and after it was reduced to zero (remanence)

The critical temperature $T_{\mathrm{c}}$ was determined magnetically by measuring the temperature where the saturated remanent magnetization in the centre of the sample dropped to zero, indicating the disappearance of persistent currents. This macroscopic criterion is much more stringent than a resistive $\mu \mathrm{V}$ criterion applied to a microbridge covering only a small fraction of the total film area.

\section{Results and discussion}

Figure 1 shows typical $B(x)$ traces for film $B$, whose principal shapes are also representative of the other samples. The upper curve is the shielding trace for an applied external field $B_{\text {ext }}=16 \mathrm{G}$; the lower one is the corresponding remanent flux distribution after reducing the external field to zero. Plotting the amount of field $B_{\text {shield }}=B_{\mathrm{cxt}}-B(x=0)$ shielded at the sample centre $(x=0)$ as a function of $B_{\text {ext }}$ results in figure 2, where data for samples $A$ and $B$ are given at $T=77 \mathrm{~K}$. The

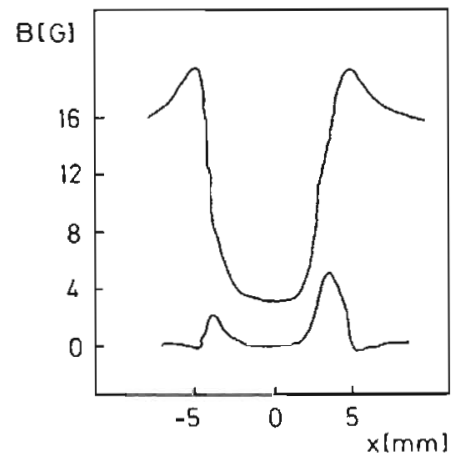

FIgure 1. A typical field distribution for an epitaxial $\mathrm{YBa}_{2} \mathrm{Cu}_{3} \mathrm{O}_{7-x}$ film on a $10 \times 10 \mathrm{~mm}^{2}(100) \mathrm{SrTiO}_{3}$ substrate. The upper curve represents the shielding field distribution for sample $\mathrm{B}$ with the external field of $16 \mathrm{G}$ applied. The lower curve is the corresponding remanent field distribution $(T=77 \mathrm{~K})$.

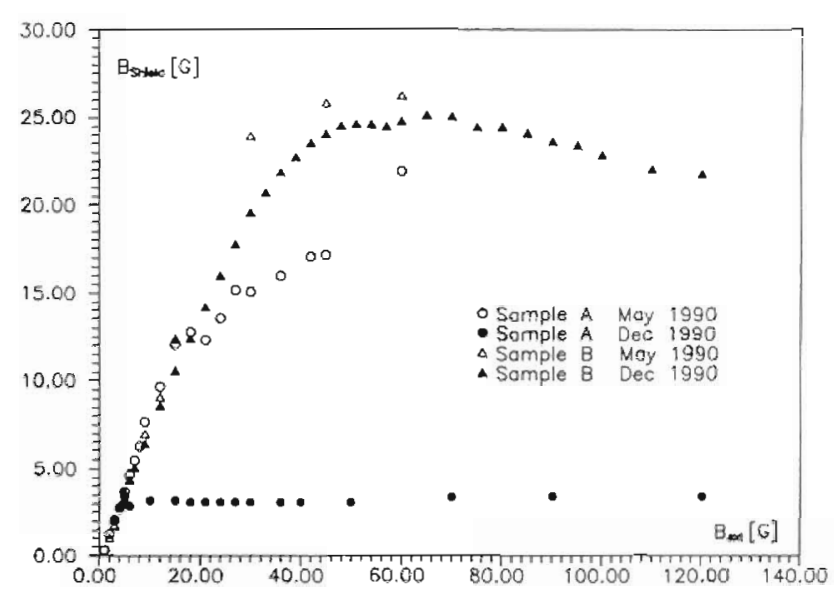

Figure 2. Influence of aging on the shielding properties for the samples that were not temperature-cycled between subsequent measurements. The symbols refer to the field that is shielded above the centre of the sample as a function of the externally applied field.

open symbols refer to the beginning of the series; the full data points were taken eight months later. At low fields a nearly linear relationship between $B_{\text {stield }}$ and $B_{\text {ext }}$ is observed. It should be noted here that in the Meissner state the initial slope of this curve is expected to be 1 , whereas the measurements yield values of about 0.8 . We attribute this deviation to stray fields resulting from the flux expulsion of the sample, which at the position of the Hall probe leads to fields with a finite normal component (the direction to which the Hall probe is sensitive).

The external field where $B_{\text {shield }}=f\left(B_{\text {exl }}\right)$ begins to deviate from the linear dependence indicates the point where the flux fronts entering the sample start to coalesce in the centre, thus yielding full penetration in the Bean critical state. The initial maximum value of $B_{\text {shield }}$ (open symbols), $23 \mathrm{G}$ and $26 \mathrm{G}$ for films $\mathrm{A}$ and $\mathrm{B}$, is a measure of the magnitude of the persistent shielding currents. (In this case 'persistent' refers to the time scale of an experimental run, typically one hour. After initial equilibration effects, changes in $B_{\text {shield }}$ were not observed during this period.) With respect to these persistent currents the quality of the two samples was comparable at the beginning of the experiments. The persistent current is estimated to be of the order of $5 \times 10^{5} \mathrm{~A} \mathrm{~cm}^{-2}$ at $T=77 \mathrm{~K}$.

The influence of aging is also apparent from figure 2. The results show that the shielding properties of film $\mathrm{B}$ with a cover layer did not change significantly after eight months, whereas film $A$ without the cover layer degraded strongly, as regards the shielding capability at $T=77 \mathrm{~K}$. The maximum value of $B_{\text {shield }}$ is reduced to $3 \mathrm{G}$, with the field distribution starting to be spatially inhomogeneous at fields above $B_{\text {ext }}=50 \mathrm{G}$ at $T=77 \mathrm{~K}$ in the latest experiment. The degrading of the film A leads to a reduction of the magnetic $T_{\mathrm{c}}$ from about $85 \mathrm{~K}$ to $81 \mathrm{~K}$. The transition temperature of film $\mathrm{B}$ with the cover layer remains unchanged, indicating the protection against aging. 
Figure 3 shows the results of the shielding in the sample centre for samples $C$ and $D$. Here, in contrast to film $\mathrm{A}$, the shiclding properties of the temperaturecycled sample $\mathrm{C}$ without a protective cover layer did not change significantly over eight months. However, the measurements further show that the field distribution starts to be inhomogeneous for external fields greater than $9 \mathrm{G}$ at $T=77 \mathrm{~K}$. The shielding of the cycled film $D$ with the cover layer improved by about $20 \%$ after eight months. Here, small inhomogeneities arose at one edge of the sample for fields of about $40 \mathrm{G}$. The transition temperature of both samples remained essentially unaffected. These results demonstrate that the film with the cover layer is again protected against aging effects from repeated temperature cycling.

The influence of cycling on the development of the shielding properties is summarized in figure 4 . Here the maximum shielded field is plotted as a function of the

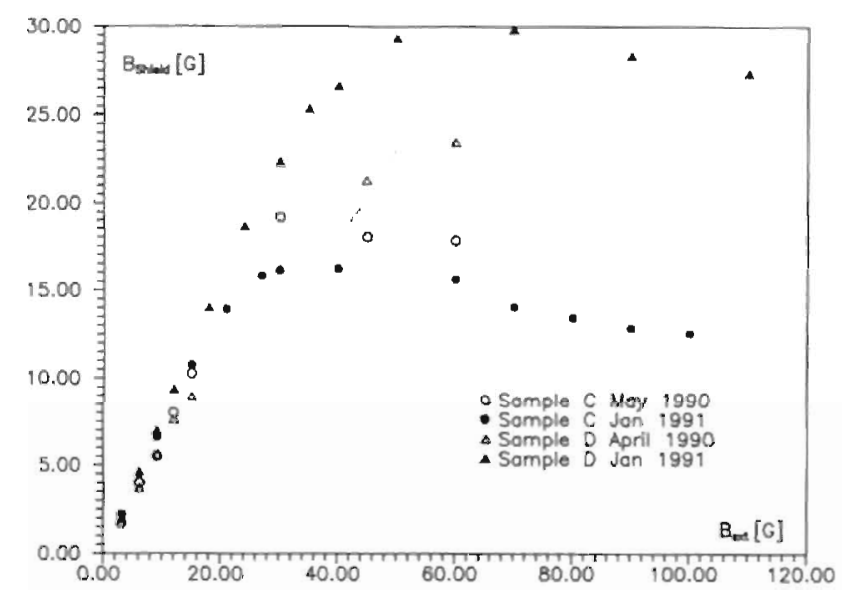

Figure 3. Influence of aging on the shielding properties for the samples that were temperature-cycled between subsequent measurements. The symbols refer to the field that is shielded above the centre of the sample as a function of the externally applied field.

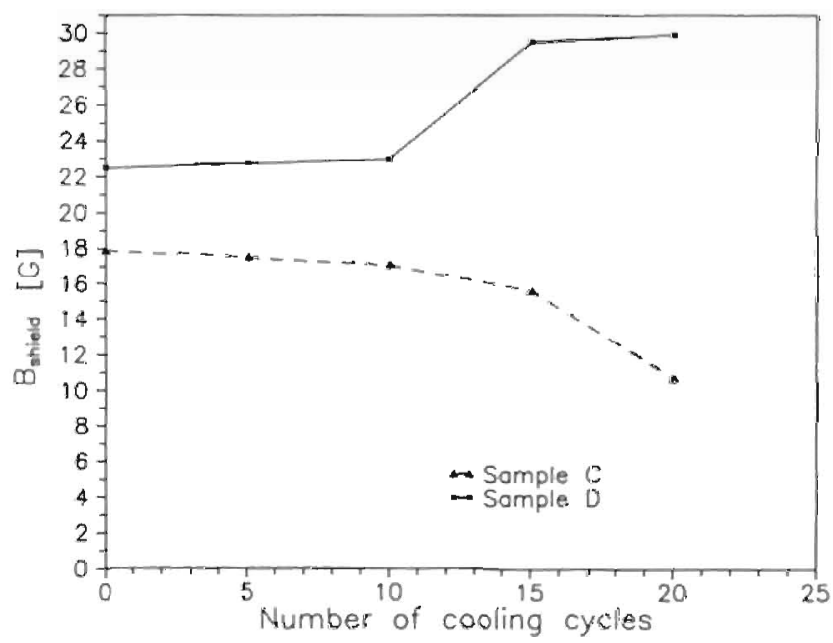

Flgure 4. Influence of temperature cycling between subsequent measurements on the shielding properties. The maximum shielded field is plotted as a function of the number of temperature cycles. cooling cycles. Whereas the uncovered film $\mathrm{C}$ degrades upon cycling, the shielding of the covered film D unexpectedly shows even a slight improvement, indicating enhanced pinning.

The remanent magnetization in the sample centre, as a function of the formerly applied field (not shown here), is reduced for the uncovered film A. For the uncovered cycled film $\mathrm{C}$, however, the maximum remanent magnetization is increased by a factor of two after eight months, a behaviour that is not well understood at present. For the films with the cover layer (B and D) the remanence remains unchanged after eight months in the comparable field range up to $60 \mathrm{G}$.

Summarizing the results of the shielding experiments at $T=77 \mathrm{~K}$ from figures 2,3 and 4 , it is seen that the maximum $B_{\text {shield }}$ of three out of four samples was not strongly influenced by degradation after a period of eight months, regardless of the treatment between the measurements. The reason for the different development of sample A cannot be specified yet. The field distribution already starts to develop strong inhomogeneities for the uncoated films $\mathrm{A}$ and $\mathrm{C}$ in fairly small fields, in contrast to the coated films $\mathrm{B}$ and $\mathrm{D}$. This demonstrates the protective influence of the cover layer. Further measurements after about 15 months underline the basic trends about the influence of aging on the four samples.

The question arises whether the inhomogeneities in the magnetic field distribution observed for the uncoated samples $\mathrm{A}$ and $\mathrm{C}$ could be due to a local destruction of superconductivity in these films in the course of aging, resulting, for example, from predominant corrosion near cracks or scratches. In order to clarify this point an additional set of data was taken at a much lower temperature, $T=15 \mathrm{~K}$. The result for $B_{\text {shield }}=f\left(B_{\text {ex }}\right)$ after eight months of aging, plotted in figure 5 , shows that obviously for $T \ll T_{\mathrm{c}}$ the shielding properties of all the four films are quite similar in the experimentally accessible field range up to $120 \mathrm{G}$. Moreover the field distribution of all four samples

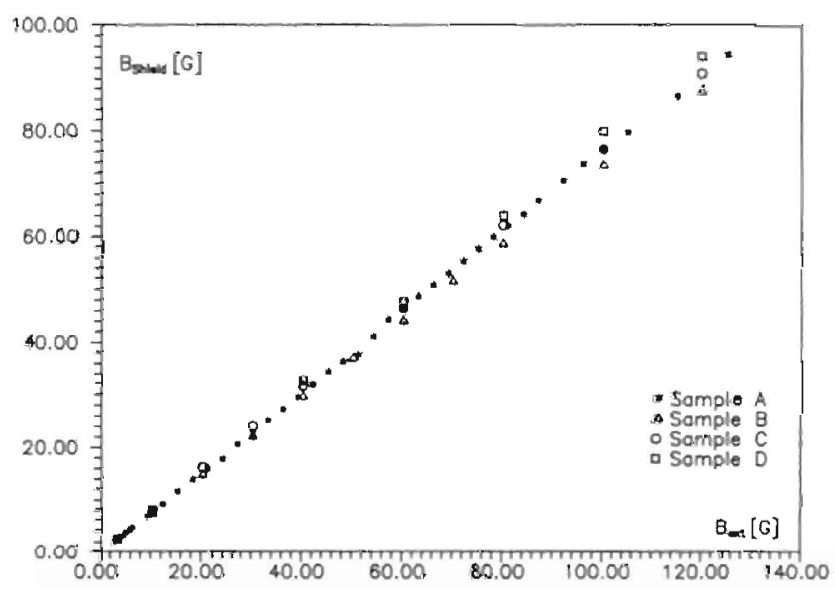

Figure 5. Comparison of the shielding properties of all four samples after eight months, in December $1990(T=15 \mathrm{~K}$ ). The symbols indicate the field that is shielded above the centre of the samples as a function of the externally applied field. 
turned out to be homogeneous at that temperature. This rules out the development of regions in the present films where superconductivity is destroyed completely; it also shows that the gradual decrease in film quality upon aging becomes most apparent at temperatures near $T_{c}$, possibly due to a change of the oxygen stoichiometry.

\section{Conclusions}

In summary we have investigated the influence of an amorphous cover layer on the aging of epitaxial $\mathrm{YBa}_{2} \mathrm{Cu}_{3} \mathrm{O}_{7-x}$ films. Although all four of the investigated films were still superconducting after more than one year without taking special precautions such as storage in dehumidified air-which is in line with the generally stated robustness of $\mathrm{YBaCuO}$ films--the two films with the cover layer were significantly more stable in the superconducting properties investigated here (persistent currents and critical temperature). Thus an amorphous coating, in addition to the expected protection against mechanical wear, improves the stability of the samples against corrosion. In view of the relatively small number of samples in the present study, more thorough investigations appear desirable to corroborate the trends outlined here.

\section{Acknowledgments}

This work was supported by the Federal Ministry for Research and Technology, project 13 N5750, and by the Forschungsschwerpunkt Baden-Württemberg.

\section{References}

[1] Mogro-Campero A, Turner L G, Bogorad A and Herschlitz R 1990 Supercond. Sci. Technol. 3537

[2] Büyüklimani T H and Simmons J H 1991 Phys. Rev. B 44 727

[3] Fröhlingsdorf J, Zander W, Stritzker B, Feile R and Leiderer P 1989 Physica C 159513

[4] Fröhlingsdor J, Zander W and Stritzker B 1988 Solid State Commun. 67965

[5] Stritzker B, Schubert J, Poppe U, Zander W, Krüger U, Lubig A and Buchal Ch $1990 \mathrm{~J}$. Less-Common. Met. 164279 